\title{
Mortality threshold for juvenile Chinook salmon Oncorhynchus tshawytscha in an epidemiological model of Ceratomyxa shasta
}

\author{
R. Adam Ray ${ }^{1,2}$, Philippe A. Rossignol ${ }^{1}$, Jerri L. Bartholomew ${ }^{2, *}$ \\ ${ }^{1}$ Department of Fisheries and Wildlife, Nash Hall, Oregon State University, Corvallis, Oregon 97331, USA \\ ${ }^{2}$ Department of Microbiology, Nash Hall, Oregon State University, Corvallis, Oregon 97331, USA
}

\begin{abstract}
The myxozoan parasite Ceratomyxa shasta is a significant pathogen of juvenile Chinook salmon Oncorhynchus tshawytscha in the Klamath River, California, USA. This parasite requires 2 hosts to complete its life cycle: a freshwater polychaete (Manayunkia speciosa) and a salmonid. The complex life cycle and large geographic area where infection occurs make it difficult to monitor and manage ceratomyxosis. We present a model for ceratomyxosis-induced mortality in O. tshawytscha, from which parameters important to the persistence of C. shasta are identified. We also experimentally quantify specific parameters from the model and identify a mortality threshold (a critical parameter), by naturally exposing native $O$. tshawytscha to C. shasta in the Klamath River. The average percent mortality that resulted from these experimental challenges ranged from 2.5 to $98.5 \%$ over an exposure dose of 4.4 to $612 \times 10^{6}$ parasites. This experiment identified a non-linear mortality threshold of $7.7 \pm 2.1 \times 10^{4}$ actinospores fish ${ }^{-1}$ for Chinook salmon from the Iron Gate Hatchery on the Klamath River. Below this threshold no mortality occurred and above it mortality increased dramatically, thus providing a target by which to reduce parasitism in emigrating juvenile O. tshawytscha.
\end{abstract}

KEY WORDS: Ceratomyxa shasta $\cdot$ Epidemiological model · Mortality threshold $\cdot$ Chinook salmon · Disease ecology $\cdot$ Myxozoan $\cdot$ Macroparasite

\section{INTRODUCTION}

Declining populations of Chinook salmon Oncorhynchus tshawytscha in the American Northwest are a major concern ecologically, economically, and sociologically. Management of this species is complicated due to the numerous biological and environmental interactions encountered at each life stage, including loss from disease. In the Klamath River, California, USA, the myxozoan parasite, Ceratomyxa shasta, is a significant pathogen of juvenile O. tshawytscha (Foott et al. 1999, 2004), with infection prevalence in outmigrant populations ranging from 30 to $60 \%$ since monitoring began in 1994 (Nichols \& True 2007, Nichols et al. 2008). C. shasta has 2 distinct environmental stages and requires 2 specific hosts to complete its life cycle (see Fig. 1). Initially described in 1950 from an outbreak in a rainbow trout hatchery (Noble 1950), it was not until 1997 that the freshwater polychaete Manayunkia speciosa was identified as the invertebrate host (Bartholomew et al. 1997). Since there is no known treatment for ceratomyxosis it is essential to identify critical points in the parasite life cycle where management strategies can be applied, thereby decreasing morbidity and mortality in out-migrating juvenile fish.

Various epidemiological models have been used to explain the complexities of host-parasite interactions and to identify the parameters necessary for the perpetuation of disease. Using these parameters one can create a system of equations and calculate the 'basic reproduction number' $\left(R_{0}\right)$, defined as the number of secondary infections arising from a primary case (Dietz 1993, Smith et al. 2007). $R_{o}$ has an intrinsic threshold 
value of 1 , and below this threshold a pathogen cannot maintain itself within the population; however, when $\mathrm{R}_{\mathrm{o}}>1$ the pathogen will spread throughout a naïve population (Macdonald 1952, Reno 1998). Thus, identifying $R_{0}$ for a particular pathogen provides information on how severe a disease outbreak is likely to be and what kind of management effort may be required to reduce it. These models have been successfully developed for infectious diseases of humans, the first being the population dynamic model of malaria developed by Ross (Ross 1911, Smith et al. 2007). Epidemiological models have been applied to diseases occurring in wildlife populations; however, they tend to be biased towards large-bodied and easily observable hosts (Dobson \& Foufopoulos 2001). One model commonly used for examining the effect of pathogens on cultured fish has been the Susceptible-Infected-Recovered (SIR) model. Although this model works well for directly transmitted pathogens such as infectious haematopoietic necrosis virus (IHNV) and the bacterium Aeromonas salmonicida (Ögüt 2003), for aquatic pathogens that require multiple hosts their application becomes increasingly complex, involving multiplicative SIR models. Thus, SIR models are useful only if the appropriate information on the various components is available (Reno 1998).

In this paper we introduce a mathematical model for the Ceratomyxa shasta life cycle, adapted from the Ross (1911) malaria population dynamic model, to identify parameters that need quantification (Table 1). We then experimentally quantified actinospore dose (A) and the parasite-induced mortality ( $\delta$ ) from that dose. From these data we calculated a mortality threshold for Chinook salmon from the Iron Gate Hatchery (IGH) on the Klamath River.

\section{MATERIALS AND METHODS}

Model development. Our model, presented in Fig. 1 and Table 1, and its system of equations were modified from a model describing the life cycle of a 'digeneantype' parasite with 2 free living stages (Dobson 1988). The number of actinospores and the parasite related mortality are directly measured in the experiments described below. Indirect measurements for the transmission rate $\left(\eta_{1}\right)$ and prevalence of infection in the Chinook salmon host $(\mathrm{C})$ were estimated from the field exposures below.

Fish and study area. Juvenile (first year age class, 0+) fall Oncorhynchus tshawytscha were obtained from the California Department of Fish and Game, IGH and were transported to the study site in aerated coolers. Fish were naturally exposed to Ceratomyxa shasta in the main stem of the Klamath River, about
1 river kilometer (Rkm) upriver from the confluence with Beaver Creek (259.1 Rkm, measured from the mouth of the river at the Pacific Ocean). The study site is about $45 \mathrm{Rkm}$ downriver from Iron Gate Dam and within a reach of the river where high densities of C. shasta have been measured (Stocking \& Bartholomew 2007). In order to increase the range of parasite

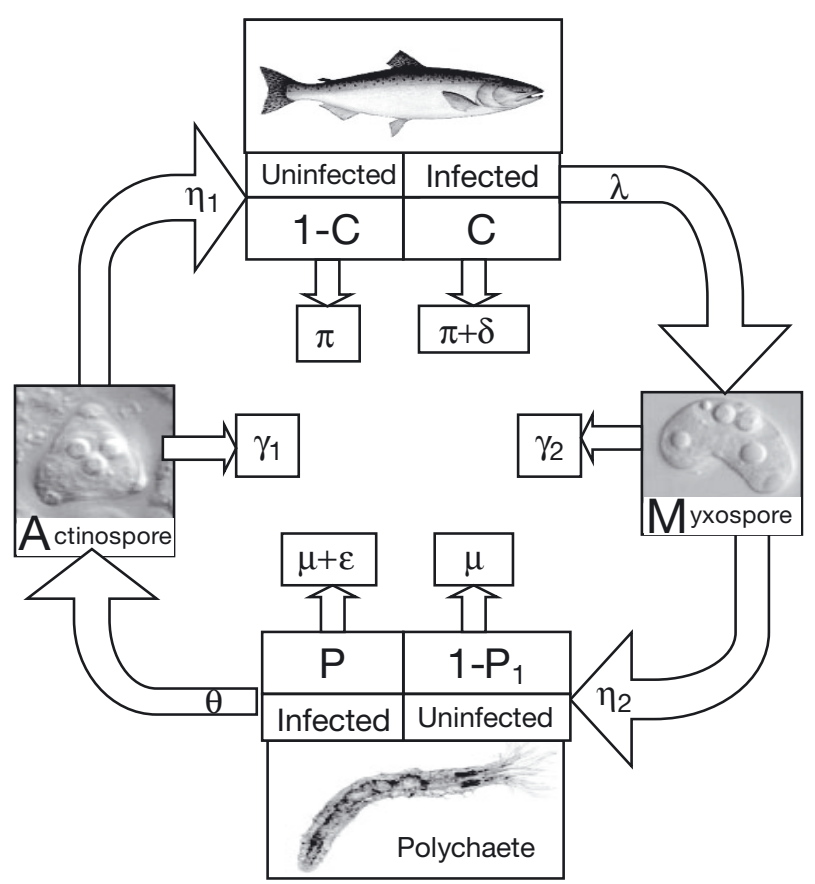

Fig. 1. Flow chart for the life cycle of Ceratomyxa shasta and its hosts. The myxospore stage (M) infects the polychaete host (P), which produces the actinospore stage (A) that infects the salmonid host (S). The experiments in this study provide a series of values for the transmission $\left(\eta_{1}\right)$ of actinospores to the Chinook salmon host (C) and the resulting mortality $(\delta)$. For further definitions of parameters see Table 1. The differential equations (Eqs. 1 to 5) are detailed in 'Results: Model development'

Table 1. Parameters used in the epidemiological model for Ceratomyxa shasta

\begin{tabular}{|ll|}
\hline Symbol & Parameter \\
\hline $\mathrm{P}$ & Proportion of infected polychaete \\
$\mathrm{C}$ & Proportion of infected Chinook salmon \\
$\mathrm{A}$ & Number of actinospores \\
$\mathrm{M}$ & Number of myxospores \\
$\eta_{1}$ & Transmission rate to salmon \\
$\eta_{2}$ & Transmission rate to polychaete \\
$\lambda$ & Myxospore production \\
$\theta$ & Actinospore production \\
$\pi$ & Natural mortality of salmon \\
$\delta$ & Parasite-induced mortality of salmon \\
$\mu$ & Natural mortality of polychaete \\
$\varepsilon$ & Parasite-induced mortality of polychaete \\
$\gamma_{1}$ & Loss of actinospores \\
$\gamma_{2}$ & Loss of myxospores \\
\hline
\end{tabular}


doses, 2 separate exposures were conducted, one in June and then again in September 2008. Fish were handled similarly before and after each exposure. Twenty unexposed IGH Chinook salmon were held as controls to ensure no background infection was present. Controls were processed in an identical manner to the exposed fish.

Fish exposures. IGH Chinook salmon were exposed in the Klamath River in eight $0.28 \times 1 \mathrm{~m}$ cylindrical PVC cages, secured to the river bed with rebar braces on both sides. Screening ( $0.64 \mathrm{~cm}$ mesh) on each end of the cage allowed for a natural flow. In June, 40 Oncorhynchus tshawytscha were each placed into Cages 1 to 4 for $72 \mathrm{~h}$ to determine the variation of parasite dose between cages. To assess dose effects, 20 fish were added to Cages 5 to 8 every $24 \mathrm{~h}$ for $3 \mathrm{~d}$, for a total of 60 fish cage $^{-1}$. To obtain low-end estimates of parasite dose and dose effects, this experiment was repeated, with some modifications, in September when a lower parasite challenge was expected. In September, 12 to 15 fish were added to each of the 8 cages at $72,48,24$, and $16 \mathrm{~h}$, for a total of 60 fish cage $\mathrm{e}^{-1}$. In June and September, each exposure group was assigned a unique fin clip to allow for separation of the groups at the end of the challenge. After exposure, each group of fish was transferred to a separate aerated cooler, transported to the Oregon State University Salmon Disease Lab and relocated to $25 \mathrm{l}$ tanks with $18^{\circ} \mathrm{C}$ specific pathogen-free water for the duration of the study ( 90 d post exposure, dpe). In the June study, salmon from Cages 5 to 8 were inadvertently combined into a single aquarium for each exposure period. Consequently, variation between cages cannot be directly measured. Preventative treatments for bacterial infections and external parasites were administered as described by Stocking et al. (2006). Fish were fed and observed twice daily. Sick and moribund fish were removed, euthanized with an overdose of MS-222 and either immediately examined for infection or frozen for future examination. Fish surviving 90 dpe were sacrificed and immediately examined for infection.

Actinospore dose. To determine the actinospore dose, the average daily water velocity during the exposure was multiplied by the average daily density of the parasite. Water velocity through each cage was measured with a Global Water Flow Probe (Global Waters) every $2 \mathrm{~h}$ for the first $24 \mathrm{~h}$ and then every $4 \mathrm{~h}$ for the remaining $48 \mathrm{~h}$. These measurements were averaged for each $24 \mathrm{~h}$ period and multiplied by the volume of the cage to determine the average daily flow. To determine the parasite density 11 of water was collected every $2 \mathrm{~h}$ by an automated water sampler (Teledyne Isco) and pooled in a $15 \mathrm{l}$ container. After $24 \mathrm{~h}$ of collection, four 11 sub-samples were collected from the container. All samples were individually filtered and 3 of the 4 samples were processed for quantification of parasite DNA by quantitative polymerase chain reaction (qPCR) as described by Hallett \& Bartholomew (2006). Each sample was analyzed in duplicate on a single 96well qPCR plate. The individual cycle threshold values from each of the 3 samples were averaged and used to estimate the number of actinospores per l of river water for a $24 \mathrm{~h}$ period. This estimate was calculated by extrapolating from a standard curve based on the value of a known number of parasites, similar to the one developed by Hallett \& Bartholomew (2006). The transmission rate of the actinospore to the salmonid host was estimated by dividing the actinospore estimate by the total number of fish infected cage ${ }^{-1}$.

Determination of infection. All dead and moribund fish and 5 randomly selected terminated fish from each exposure group were microscopically examined for the myxospore stage of Ceratomyxa shasta. Material from the posterior intestine was collected with a sterilized inoculating loop, placed on a microscope slide and examined at $200 \times$ magnification for up to $3 \mathrm{~min}$ (Bartholomew 2002). If no spores were observed, approximately $5 \mathrm{~mm}$ of intestinal tissue was removed and frozen for PCR analysis as described by Palenzuela et al. (1999). The prevalence of infection in the Chinook salmon host was estimated by summing the observed ceratomyxosis-related mortalities and the fish that were found positive for infection by PCR.

Data analysis. Chinook salmon that died after 5 dpe were included in the analysis; earlier mortalities were ascribed to non-Ceratomyxa shasta causes. Percent mortality was calculated by combining fish that were positive for $C$. shasta either by microscopy or PCR analysis and dividing the number of positive fish by the total number exposed in each cage for each exposure period. The percent of infection mortality for each cage in an exposure period was determined for the entire observational period (90 dpe). Statistical analysis was conducted using S-plus 8.0 (TIBCO software). KaplanMeier survival curves were analyzed by Cox proportional hazards test, using score (logrank) tests to determine the difference in mortalities between cages and exposure periods. One sample, pair wise $t$-tests and one-way ANOVAs were used to determine the variations in flow between days and between cages.

\section{RESULTS}

\section{Model development}

The structure and parameters of this model (Fig. 1 and Table 1, respectively) are represented by a flow diagram based on the life cycle of Ceratomyxa shasta. A series of 4 differential equations was developed that 
describes the transmission and mortality rates at each stage in the life cycle. For the development of these equations we assume C. shasta is a microparasite. For definitions of all parameters used in the equations see Table 1.

Salmon infection and mortality. Transmission of actinospores to uninfected salmonid host, less the natural and parasite-induced mortality of the host.

$$
\frac{\mathrm{dC}}{\mathrm{d} t}=\eta_{1} \mathrm{~A}(1-\mathrm{C})-\pi(1-\mathrm{C})-(\pi+\delta) \mathrm{C}
$$

Myxospore transmission and mortality. Production of myxospore from infected salmon, less those spores transmitted to uninfected polychaetes and spores that are lost to the environment.

$$
\frac{\mathrm{dM}}{\mathrm{d} t}=\lambda \mathrm{C}-\gamma_{2} \mathrm{M}-\eta_{2} \mathrm{M}(1-\mathrm{P})
$$

Polychaete infection and mortality. Transmission of myxospores to uninfected polychaetes, less the natural and parasite induced mortality of the polychaete host.

$$
\frac{\mathrm{dP}}{\mathrm{d} t}=\eta_{2} \mathrm{M}(1-\mathrm{P})-\mu(1-\mathrm{P})-(\mu+\varepsilon) \mathrm{P}
$$

Actinospore transmission and mortality. Production of actinospores from infected polychaete, less spores transmitted to uninfected salmon and spores that are lost to the environment.

$$
\frac{\mathrm{dA}}{\mathrm{d} t}=\theta \mathrm{P}-\gamma_{1} \mathrm{~A}-\eta_{1} \mathrm{~A}(1-\mathrm{C})
$$

Eqs. (1) to (4) can be solved for the equation for $R_{o}$ (Eq. 5). This equation describes the transmission of myxospore to polychaete $\left(\mathrm{T}_{\mathrm{MP}}\right)$ and actinospore to salmonid $\left(\mathrm{T}_{\mathrm{AC}}\right)$ divided by the mortalities for both spore stages $\left(M_{M}\right.$ and $\left.M_{A}\right)$ and hosts $\left(M_{P}\right.$ and $\left.M_{C}\right)$. The experiments conducted in this study provided a range of measurements for the parameters in Eq. (1): actinospore dose, the resulting parasite-induced mortality and indirect measurements of the transmission of the

Table 2. Comparison of total Ceratomyxa shasta dosage and resulting mortality

\begin{tabular}{|c|c|c|c|c|}
\hline \multirow{2}{*}{$\begin{array}{l}\text { Exposure } \\
\text { duration } \\
\text { (h) }\end{array}$} & \multicolumn{2}{|c|}{ June } & \multicolumn{2}{|c|}{ September } \\
\hline & $\begin{array}{l}\text { Actinospore } \\
\text { dose }\left(\times 10^{6}\right)\end{array}$ & $\begin{array}{l}\text { Mortality } \\
(\%)\end{array}$ & $\begin{array}{l}\text { Actinospore } \\
\text { dose }\left(\times 10^{6}\right)\end{array}$ & $\begin{array}{l}\text { Mortality } \\
(\%)\end{array}$ \\
\hline 16 & NA & NA & $4.4( \pm 1.3)$ & $2.5( \pm 7.1)$ \\
\hline 24 & $535.4( \pm 41.5)$ & $84.7^{\mathrm{a}}$ & $6.6( \pm 2.0)$ & $16.7( \pm 6.6)$ \\
\hline 48 & $594.5( \pm 48.2)$ & $98.5^{\mathrm{a}}$ & $13.2( \pm 3.7)$ & $17.7( \pm 13.3)$ \\
\hline 72 & $612.0( \pm 51.0)$ & $94.2( \pm 2.7)$ & $153.2( \pm 4.3)$ & $34.9( \pm 12.6)$ \\
\hline
\end{tabular}
of Iron Gate Hatchery Chinook salmon Oncorhynchus tshawytscha exposed in the Klamath River, California, USA, for different durations in June and September 2008. NA: not available actinospore to the salmonid and the proportion of salmonid population infected.

$$
\begin{aligned}
\mathrm{R}_{0} & =\frac{\lambda \eta_{1}(1-\mathrm{P}) \theta \eta_{2}(1-\mathrm{C})}{[\mu+(\mu+\varepsilon)][\pi+(\pi+\delta)]\left[\eta_{1}(1-\mathrm{C})+\gamma_{1}\right]\left[\eta_{2}(1-\mathrm{P})+\gamma_{2}\right]} \\
& =\frac{\mathrm{T}_{\mathrm{MP}} \mathrm{T}_{\mathrm{AC}}}{\mathrm{M}_{\mathrm{P}} \mathrm{M}_{\mathrm{C}} \mathrm{M}_{\mathrm{M}} \mathrm{M}_{\mathrm{A}}}
\end{aligned}
$$

We evaluated parasite-induced mortality following different exposure durations and expect these variables to be linearly proportionate. Average percent mortality for the June 72, 48 and $24 \mathrm{~h}$ exposure groups was 94.2, 98.5 and $84.7 \%$, respectively. The average percent mortality of fish in Cages 1 to 4, exposed for $72 \mathrm{~h}$, was $95.1 \pm$ $2 \%$, and did not differ significantly between these 4 groups (score (logrank) df $=3, p=0.504$ ). The average percent mortality of the pooled fish exposed for $72 \mathrm{~h}$ (90.6\%, Cages 5 to 8 ) was not statistically different from that observed in Cages 1 to 4 (score (logrank) df $=4, \mathrm{p}=$ $0.465)$, indicating similarly minimal variability in mortality between Cages 5 to 8 . Fish from Cages 5 to 8 were inadvertently combined into aquaria for each holding group, thereby prohibiting the calculation of variance in parasite-induced mortality. However, given the high actinospore dose and the limited variability between the $72 \mathrm{~h}$ exposure in June, it can be assumed that there was minimal variability between these cages and thus these exposures were not repeated. Although the difference in mortality between all 3 exposure periods was statistically significant (score (logrank) df $=2, \mathrm{p}<0.001$ ) (Table 2), biologically, all 3 periods resulted in mortality too great to identify a mortality threshold.

In September, average mortality was 34.9, 17.7, 16.7 and $2.5 \%$, for the $72,48,24$ and $16 \mathrm{~h}$ exposure periods, respectively. Differences in mortality between cages were not significantly different for the 72 and $24 \mathrm{~h}$ exposure periods (score (logrank) df $=7, \mathrm{p}=0.147$ and 0.874 , respectively), but a statistical difference was observed between the 48 and $16 \mathrm{~h}$ exposures (score (logrank) $\mathrm{df}=7, \mathrm{p}=0.029$ and 0.009 , respectively). These differences are a result of elevated mortalities in a single cage for each exposure period. From the $48 \mathrm{~h}$ exposure group, 7 fish from Cage 3 died $(\sim 50 \%)$ compared to $20 \%$ or less for the remaining cages. In the $16 \mathrm{~h}$ exposure group, 3 fish (20\%) succumbed to ceratomyxosis in Cage 7 compared to no parasite-related mortality in any other cage. Percent mortality was significantly different between the 
72 and $48 \mathrm{~h}$ exposures (score (logrank), df $=1, \mathrm{p}<$ 0.001 ) and the 24 and $16 \mathrm{~h}$ exposures (score (logrank) $\mathrm{df}=1, \mathrm{p}=0.001$ ), but not between the 48 and $24 \mathrm{~h}$ exposures (score (logrank) df $=1, p=0.759$ ). Mortality from ceratomyxosis was higher in June than September; however, minimal variability occurred between cages during both exposure periods (Fig. 2). All the fish that survived the duration of this study were determined to be negative for infection by the PCR assay; therefore we assume that the proportion of infected Chinook salmon is equal to the observed parasiteinduced mortality. The results from these 2 exposure periods provide a range of values for our model for parasite-induced mortality, and also, in combination with the PCR assay results, an estimate of the proportion of Chinook salmon that became infected. We conclude that salmon mortality is not a constant, but is logarithmically proportional to the exposure duration.

\section{Actinospore dose}

The actinospore dose was calculated from the product of the average daily water velocities and average daily parasite density measured over the exposure duration. The average water velocity in June (5.38 \pm $0.74 \mathrm{l} \mathrm{s}^{-1}$ ) was significantly greater than the average velocity in September $\left(3.93 \pm 0.971 \mathrm{~s}^{-1}, t\right.$-test $\left.\mathrm{p}<0.05\right)$. The average daily parasite density in June varied greatly from Day 1 to Day $3\left(28,146,1258\right.$ spores $\mathrm{l}^{-1}$, respectively). In September, the average daily parasite density was lower, yet more consistent between days $\left(21,20,16\right.$ spores $\mathrm{l}^{-1}$, respectively), than in June. The

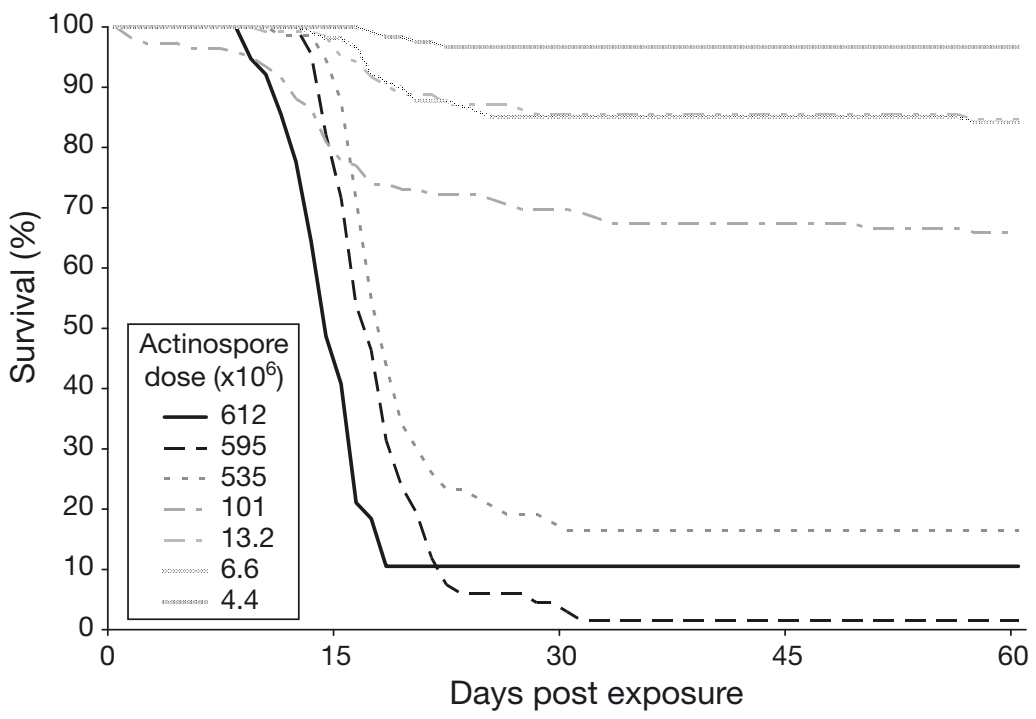

Fig. 2. Ceratomyxa shasta infecting Oncorhynchus tshawytscha. Survival curves of Iron Gate Hatchery Chinook salmon exposed to various doses of C. shasta in the Klamath River, California, USA, in June and September 2008. Curves are identified by the average actinospore dose received, in millions of actinospores total actinospore dose ranged from a maximum of $612 \times 10^{6}$ spores, during the June $72 \mathrm{~h}$ exposure, to a minimum of $4.4 \times 10^{6}$ spores during the September $16 \mathrm{~h}$ exposure (Table 2). These measurements provide an array of actinospore doses that can be utilized in the model.

A lethal infectious dose fish ${ }^{-1}$ was determined by dividing the total actinospore dose by the total number of fish cage $^{-1}$, adjusting for the increasing fish density as the experiment progressed. The individual dose ranged, approximately, from $0.05 \times 10^{6}$ (September, $16 \mathrm{~h}$ exposure) to $12.8 \times 10^{6}$ (June $72 \mathrm{~h}$ exposure) spores fish ${ }^{-1}$, and a non-linear relationship with percent mortality can be observed (Fig. 3). We conclude that the mortality threshold in IGH Oncorhynchus tshawytscha was $7.7 \pm 2.1 \times 10^{4}$ actinospores fish ${ }^{-1}$.

\section{DISCUSSION}

We developed an epidemiological model for the Ceratomyxa shasta life cycle as a tool for evaluating which potential management strategies might prove most effective at improving the survival of out-migrating juvenile salmonids in the Klamath River. Using this model we identified parameters and developed a system of linearizable equations necessary for transmission of this parasite. Values for many of these parameters had not been previously determined, and we chose to focus on infection in the salmonid host, utilizing sentinel fish exposures and molecular techniques to quantify this portion of the model. Thus the critical parameters investigated in the exposure experiments were: actinospore dose, proportion of salmonids infected and parasite-induced mortality (Fig. 1). From these values a mortality threshold for IGH Chinook salmon held at $18^{\circ} \mathrm{C}$ was determined to be $7.7 \pm 2.1 \times 10^{4}$ actinospores fish $^{-1}$, above which mortality increases non-linearly. Although this threshold may vary from year to year, it provides the first estimate for a C. shasta lethal dose for a resistant strain of fish. Identifying a threshold significantly above zero is important to disease management as it provides a target for reducing the in-river parasite burden that does not require complete eradication of the parasite.

Quantification of the dose-mortality relationship is an important interaction in disease ecology and is necessary for modeling diseases in natural populations (Crofton 1971, Anderson \& May 1978). It has been qualitatively shown that fish 


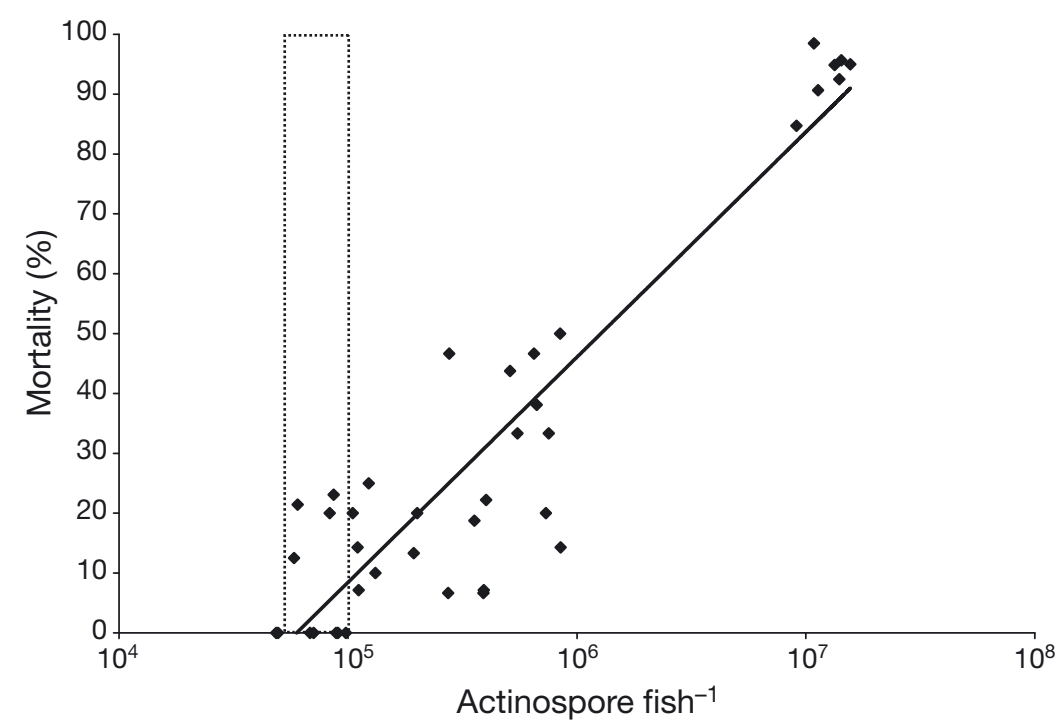

Fig. 3. Relationship between Ceratomyxa shasta induced mortality in Iron Gate Hatchery Chinook salmon Oncorhynchus tshawytscha and estimated actinospore dose fish ${ }^{-1}$. The $x$-axis is log transformed to better represent the wide range of actinospore doses. The $\mathrm{R}^{2}$ value is 0.858 and the regression equation is $y=16.335 \times \ln (x)-179.62$. The dotted box represents the range of values quantified for the mortality threshold

River salmon receiving a lower exposure in the Trinity River and having a shorter migration in the main stem of the Klamath River, this strain is likely to be more susceptible to the parasite than IGH salmon, as evident by the differences in morality thresholds. This inbasin variation in susceptibility suggests that the mortality threshold needs to be quantified for each strain in order to be used for management purposes.

The observation of a non-linear mortality threshold is crucial to understanding the epidemiology of the parasite. In general, parasites are considered either microparasites or macroparasites. For a microparasite, prevalence of infection is sufficient to evaluate parasitism in the host, and parasite dose and host mortality are not proportional. In a macroparasite relationship, parasite dose and host mortality are non-linearly related and the frequency distribution of the parasite is more important than prevalence within the host (Crofton 1971,

from waters where Ceratomyxa shasta is endemic are less susceptible to infection and mortality (reviewed by Bartholomew 1998). The first estimation of infectious dose was semi-quantitatively determined by increasing the density of fish in a given volume of water, thereby decreasing the ratio of parasites to fish. The resulting decrease in ceratomyxosis-related mortalities suggested that a single actinospore can cause mortality in a susceptible strain of rainbow trout Oncorhynchus mykiss (Ratliff 1983). Recent developments of laboratory challenge methods validated this prediction for susceptible rainbow trout using a quantified infectious dose (Bjork \& Bartholomew 2009). In contrast, individual IGH O. tshawytscha exposed to $5 \times 10^{3}$ actinospores under identical conditions failed to become infected, indicating a higher mortality threshold for this strain (Bjork \& Bartholomew 2009). To achieve an infectious dose great enough to induce mortality in these less susceptible fish, Foott et al. (2007) conducted field exposures and quantified parasite density by qPCR. In their study, Trinity River Chinook salmon were exposed to approximately $1.4 \times 10^{4}$ actinospores fish $^{-1}$, resulting in $22 \%$ mortality (Foott et al. 2007). Compared to the IGH Chinook salmon in our study, the morality threshold for the Trinity River salmon was about 5-fold lower. Although the Trinity River is a major tributary to the Klamath River, the levels of C. shasta are lower and the prevalence of infection in out-migrating juvenile salmon is about 1 to $3 \%$ (Nichols et al. 2008, 2009). As a result of the Trinity
Anderson \& May 1979, May \& Anderson 1979, Dobson 1988). The presence of a mortality threshold indicates a macroparasitic relationship between Ceratomyxa shasta and the salmonid host. Yet the ability of $C$. shasta to replicate within the salmonid host is representative of microparasitic relationships. Recognition of when C. shasta behaves as a macroparasite versus a microparasite within the disease cycle is critical to further the development of this model.

Application of this model is currently limited by the lack of data for various parameters. For example, estimates for the emigration rate of juvenile salmonids are highly variable, and this directly affects the potential exposure dose. A recent radio-telemetry survey documented that juvenile IGH Chinook salmon reach the estuary in a median time of 10 d (Foott et al. 2009). However, another study estimated the median travel time of coded wire-tagged IGH juvenile Chinook salmon released between 1993 and 2001 to be $32 \mathrm{~d}$ (Wallace 2004), over a 3 -fold difference in travel time. Our study attempted to account for this difference in migration rate by using various exposure durations to reflect different exposure doses. Another limitation is that our current model does not specifically incorporate environmental or genetic variables, such as water temperature, velocity, or genetic variations within the hosts or parasites. Water temperature has been demonstrated to greatly affect mortalities from ceratomyxosis (Udey et al. 1975), yet we do not know how it affects the other parameters in the model. Similarly, 
genotypic variations in Ceratomyxa shasta that relate to its specificity for the salmonid host have recently been identified (Atkinson \& Bartholomew 2010a,b). These observations open avenues to better understanding ecological implications of environmental and genetic differences and how they can be incorporated into the dynamics of this host-parasite system.

The principal objective of this study was to develop a model and identify the parameters required for the propagation of Ceratomyxa shasta. The experiments in this study provided a range of values for 3 parameters, which allowed us to identify a mortality threshold for juvenile Chinook salmon. Once all the parameters are quantified, the model and resulting system of equations can be used to determine the relative sensitivity of each parameter; predict how different management strategies may influence host-parasite interactions; and, examine the resilience and reactivity of the system after management actions have been implemented (Neubert \& Caswell 1997, Hosack et al. 2009).

Acknowledgements. We thank fellow Oregon State University (OSU) researchers Charlene Hurst and Zachary Semerikov for assistance in field experiments, Donald Stevens for guidance in cage construction, Richard Holt for assistance with fish care, Gerri Buckles for GPCR advice and California Department of Fish and Game, Kim Ruschton and the staff at Iron Gate Hatchery for providing Chinook salmon. Sascha Hallett (OSU), Carl Schreck (Oregon Cooperative Fishery Unit) and Josh Strange (Yurok Tribal Fisheries Program) are thanked for comments and editorial suggestions in this manuscript. We express our gratitude to Fisher's RV Park for access to the Klamath River to conduct this study. Funding for this study was provided by the Bureau of Reclamation.

\section{LITERATURE CITED}

Anderson RM, May RM (1978) Regulation and stability of host-parasite population interactions. J Anim Ecol 47: 219-247

Anderson RM, May RM (1979) Population biology of infectious diseases: Part I. Nature 280:361-367

Atkinson SD, Bartholomew JL (2010a) Disparate infection patterns of Ceratomyxa shasta (Myxozoa) in rainbow trout Oncorhynchus mykiss and Chinook salmon Oncorhynchus tshawytscha correlate with ITS-1 sequence variation in the parasite. Int J Parasitol 40:599-604

Atkinson SD, Bartholomew JL (2010b) Spatial, temporal and host factors structure the Ceratomyxa shasta (Myxozoa) population in the Klamath River basin. Infect Genet Evol 10:1019-1026

Bartholomew JL (2002) Salmonid ceratomyxosis. In: FHS Blue Book: Suggested procedures for the detection of certain finfish and shellfish pathogens. 2007 edn. American Fisheries Society-Fish Health Section (AFS-FHS), Bethesda, $\mathrm{MD}$

Bartholomew JL, Whipple MJ, Stevens DG, Fryer JL (1997) The life cycle of Ceratomyxa shasta, a myxosporean parasite of salmonids, requires a freshwater polychaete as an alternate host. J Parasitol 83:859-868
Bartholomew JL (1998) Host resistance to infection by the myxosporean parasite Ceratomyxa shasta: a review. J Aquat Anim Health 10:112-120

Bjork SJ, Bartholomew JL (2009) Effects of Ceratomyxa shasta dose on a susceptible strain of rainbow trout and comparatively resistant Chinook and coho salmon. Dis Aquat Org 86:29-37

Crofton HD (1971) A quantitative approach to parasitism. Parasitology 62:179-193

Dietz K (1993) The estimation of the basic reproduction number for infectious diseases. Stat Methods Med Res 2:23-41

> Dobson AP (1988) The population biology of parasite-induced changes in host behavior. Q Rev Biol 63:139-165

$>$ Dobson AP, Foufopoulos J (2001) Emerging infectious pathogens of wildlife. Phil Trans R Soc Lond B 356:1001-1012

Foott JS, Stone R, True K (2007) Relationship between Ceratomyxa shasta and Parvicapsula minibicornis actinospore exposure in the Klamath River and infection in juvenile Chinook salmon. FY 2006 Investigational report. US Fish and Wildlife Service, CA-NV Fish Health Center, Anderson, CA

Foott JS, Williamson JD, True KC (1999) Health, physiology, and migration characteristics of Iron Gate Hatchery Chinook, 1995 releases. US Fish and Wildlife Service, CA-NV Fish Health Center, Anderson, CA

Foott JS, Harmon R, Stone R (2004) Effect of water temperature on non-specific immune function and ceratomyxosis in juvenile Chinook salmon and steelhead from the Klamath River. Calif Fish Game 90:71-84

Foott JS, Stutzer G, Fogerty R, Hansel HC, Juhnke SD, Beeman JW (2009) Pilot study to access the role of Ceratomуха shasta infection in mortality of fall-run Chinook smolts migration through the lower Klamath River in 2008. US Fish and Wildlife Service-US Geological Survey Technical report, US Fish and Wildlife Service, CA-NV Fish Health Center, Anderson, CA

> Hallett SL, Bartholomew JL (2006) Application of a real-time PCR assay to detect and quantify the myxozaon parasite Ceratomyxa shasta in river water samples. Dis Aquat Org 71:109-118

> Hosack GR, Li HW, Rossignol PA (2009) Sensitivity of system stability to model structure. Ecol Model 220:1054-1062

Macdonald G (1952) The analysis of equilibrium in malaria. Trop Dis Bull 49:813-829

May RM, Anderson RM (1979) Population biology of infectious diseases: Part II. Nature 280:455-461

Neubert MG, Caswell H (1997) Alternatives to resilience for measuring the responses of ecological systems to perturbations. Ecology 78:653-665

Nichols K, True K (2007) Monitoring incidence and severity of Ceratomyxa shasta and Parvicapsula minibicornis infections in juvenile Chinook salmon (Oncorhynchus tshawytscha) and Coho salmon (O. kisutch) in the Klamath River. FY 2006 Investigational report. US Fish and Wildlife Service, CA-NV Fish Health Center, Anderson, CA

Nichols K, True K, Fogerty R, Ratcliff L (2008) Klamath River juvenile salmonid health monitoring, April-August 2007. FY 2007 Investigational report. US Fish and Wildlife Service, CA-NV Fish Health Center

Nichols K, True K, Fogerty R, Ratcliff L, Bolick A (2009) Myxosporean parasite (Ceratomyxa shasta and Parvicapsula minibicornis) prevalence and severity in Klamath River Basin juvenile Chinook (Oncorhynchus tshawytscha) and Coho salmon (O. kisutch), April-August 2008. US Fish and Wildlife Service, CA-NV Fish Health Center, Anderson, CA

$>$ Noble ER (1950) On a myxosporidian (Protozoan) parasite of California trout. J Parasitol 36:457-460 
Ogüt H (2003) Modeling of fish disease dynamics: a new approach to an old problem. Turkish J Fish Aquat Sci 3: $67-74$

Palenzuela O, Trobridge G, Bartholomew JL (1999) Development of a polymerase chain reaction diagnostic assay of Ceratomyxa shasta, a myxosporean parasite of salmonid fish. Dis Aquat Org 36:45-51

Ratliff DE (1983) Ceratomyxa shasta: longevity, distribution, timing, and abundance of the infective stage in central Oregon. Can J Fish Aquat Sci 40:1622-1632

Reno PW (1998) Factors involved in the dissmenination of disease in fish populations. J Aquat Anim Health 10:160-171

Ross R (1911) The prevention of malaria. John Murray, London

Smith DL, McKenzie FE, Snow RW, Hay SI (2007) Revisiting the basic reproductive number for malaria and its implications for malaria control. PLoS Biol 5:631-642

Stocking RW, Bartholomew JL (2007) Distribution and habitat characteristics of Manayunkia speciosa and infection prevalence with the parasite Ceratomyxa shasta in

Editorial responsibility: Julie Bebak,

Auburn, Alabama, USA the Klamath River, Oregon-California. J Parasitol 93: $78-88$

Stocking RW, Holt RA, Foott JS, Bartholomew JL (2006) Spatial and temporal occurrence of the salmonid parasite Ceratomyxa shasta in the Oregon-California Klamath River Basin. J Aquat Anim Health 18:194-202

Udey LR, Fryer JL, Pilcher KS (1975) Relation of water temperature to ceratomyxosis in rainbow trout (Salmo gairdneri) and coho salmon (Oncorhynchus kisutch). J Fish Res Board Can 32:1545-1551

Wallace M (2004) Natural vs. hatchery proportions of juvenile salmonids migrating through the Klamath River estuary and monitor natural and hatchery juvenile salmonid emigration from the Klamath River Basin: July 1, 1998 through June 30, 2003. Final performance report-Federal Aid in Sport Fish Restoration Act Project No. F-51-R6. California Department of Fish and Game Inland and Anadromous Sport Fish Management and Research, Klamath River Basin Juvenile Salmonid Investigations, Arcata, CA

Submitted: November 4, 2009; Accepted: August 26, 2010 Proofs received from author(s): October 11, 2010 